\title{
Effects of laser pulse energy and annealing process on physical properties of nanostructured $\mathrm{SiO}_{2}$ prepared by pulse laser deposition Jafer Fahdel Odah
}

\author{
Department of Physics, College of Science, University of Al-Muthanna, Samawa, Iraq \\ E-mail address:hajasafa@yahoo.com
}

Keywords: $\mathrm{SiO}_{2}$ thin film, pulse laser deposition, annealing temperature.

\begin{abstract}
Silicon dioxide thin film of different thicknesses has been grown on glass substrate by pulsed laser deposition technique with and without annealing temperature under the vacuum pressure of $8 \times 10^{-2}$ mbar. The optical properties such as the absorption, and transmission spectra have been studied for the prepared $\mathrm{SiO}_{2}$ thin film before and after annealing temperature. From the transmission spectra, the optical gap and linear refractive index of the $\mathrm{SiO}_{2}$ thin film was determined. The structure of the $\mathrm{SiO}_{2}$ thin film was tested with X-Ray diffraction, it was formed to be amorphous structure before annealing temperature. The effects of laser pulse energy on the optical properties has been studied before and after annealing temperature. It is found that almost optical properties depends on the laser pulse energy and increases with increasing laser pulse energy and they are enhanced with the annealing temperature.
\end{abstract}

\section{INTRODUCTION}

Pulsed-laser deposition has been used to deposit an extraordinarily wide range of materials [1]. Historically, the most important application of PLD has been in the field of high temperature superconducting thin films [2]. In addition to superconductor films, PLD of material oxides has also been shown to produce high quality ferroelectric[3,4], magnetoresistive materials $[5,6]$. In the field of semiconductors, PLD has been used to deposit a wide range of materials, e.g. SiGe- [7] and GaAs-based [8] alloys, II-VI compounds [9], and Group III-Nitrides [10,11,12]. PLD has also been used to deposit some of optical materials, for example: $\mathrm{ZnO}$ as a piezo-electric, piezo-optical, transparent conductor [13]; $\mathrm{TiO}_{2}$ as antireflection coatings on Silicon [14]; rare-earth-doped phosphate glasses for optical waveguide applications [15]; and hafnia, yttria, and zirconia for optical multilayer structures [16]. The final area of significant PLD research is in the field of hard coatings, like boron nitride [11], carbon nitride [17,18], and diamond-like carbon [19]. The energetic nature of the depositing vapour assumed to be responsible for enabling the growth of the hard phases, which are not thermodynamically stable under the growth conditions of conventional techniques $[20,17]$. Silicon dioxide films are used in a variety of applications in the electronics and photonics industries, with a corresponding range of desired properties [21]. For electronics applications, the silicon dioxide insulating Iayer is used in silicon-based MOS structures [22]. A second application of silica films is as the basis for optical waveguides in optical integrated circuits. A third application of silicon dioxide films is in the formation of multilayer dielectric stacks for use as wavelength-selective optical filters and mirrors. Silicon dioxide films for optics and photonics applications must be of high purity and have low surface roughness [21]. Fagaraasy et al. produced the best $\mathrm{SiO}_{2}$ thin-films grown by PLD [23,24,25]. The quality of films deposited at low temperatures is expected to be improved by increasing the kinetic energy of the depositing species, thus reducing the need for additional thermal excitation in the growth process [21]. Fogarassy et al. obtained stoichiometric $\mathrm{SiO}_{2}$ films by ArF-laser ablation of fused silica in a $10^{-5}$ Torr vacuum. However, the films grown to-date by PLD from a fused silica target have been contaminated by significant quantities of $0.1-10 \mu \mathrm{m}$ particulates [23,26,27].

\section{EXPERIMENTAL DETAILS}

A typical set-up for Pulse Laser Deposition (PLD) is schematically shown in Figure 1. In this study, $\mathrm{SiO}_{2}$ was used as targets with diameter of $2 \mathrm{~cm}$ and thickness of $1 \mathrm{~cm}$ was fixed at the top 
chamber. Glass substrate has been used as substrate material to prepare $\mathrm{SiO}_{2}$ thin films. The cleaning of the substrates is very important to ensure surface free from contamination particles such as grease, absorber water molecules. The glass substrates has been ultrasonically cleaned in acetone and dried into oven. $\mathrm{SiO}_{2}$ thin films were produced by Pulse Laser Deposition (PLD). In order to optimize the best location of the substrates on holder, the influence of the substrate to target distance on the structural and optical properties of $\mathrm{SiO}_{2}$ thin films produced by Pulse Laser Deposition (PLD) in argon atmosphere was studied. The $\mathrm{SiO}_{2}$ films were grown during 5 min onto glass microscope slides diametrically on the top plate substrate holder, after that they were annealed at temperature of $500^{\circ} \mathrm{C}$. The base pressure in the chamber and the working pressure were $2.0 \times 10^{-5}$ mbar and $8 \times 10^{-2}$ mbar, respectively. A series of films were synthesized under argon atmosphere with power $500 \mathrm{~mJ}$ and the working pressure $\left(\mathrm{P}_{\mathrm{w}}\right)$ were kept constants and equal, $\mathrm{P}_{\mathrm{w}}=8.0 \times 10^{-2}$ mbar. In this study, a variety of characterization techniques have been used to investigate the structural, optical and electrical properties of the thin films before and after the annealing process. Of special interest was the determination of the structure from X-ray diffraction and the film thicknesses from optical interference fringes. Optical parameters from UV-Visible absorbance spectrum in the spectral range (200 -850) nm. Optical method has been implemented for thickness measurements and in the flowing is explained in details:

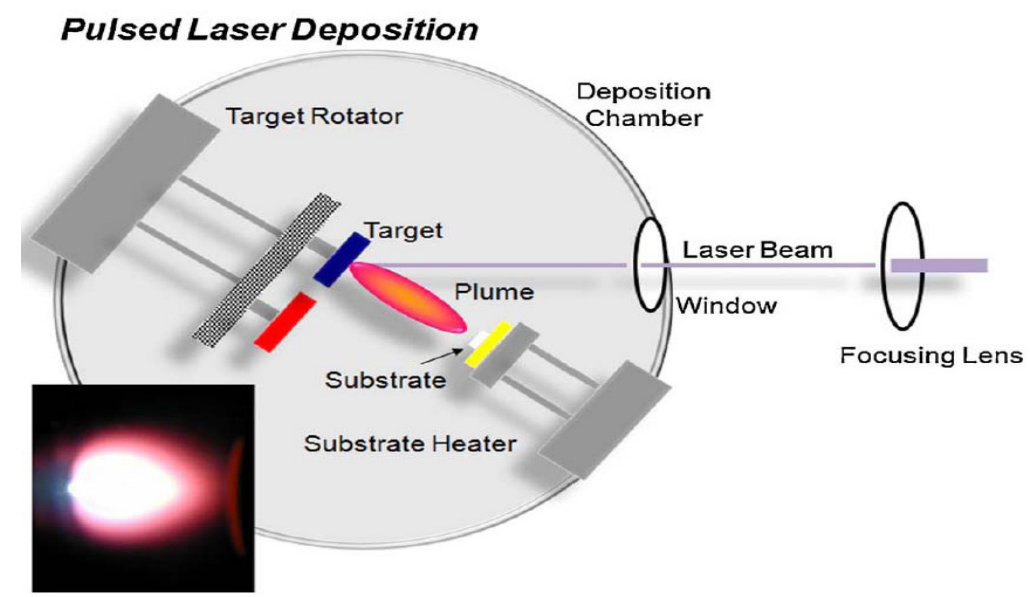

Figure 1: Schematic diagram of a typical laser deposition set-up.

The thickness of $\mathrm{SiO}_{2}$ thin film was measured by using an optical interferometer method employing He-Ne laser $0.632 \mu \mathrm{m}$ with incident angle $45^{\circ}$ as shown schematically in Figure 2 . This method depends on the interference of the laser beam reflected from thin film surface and then substrate, the films thickness $t$ can be calculated using the following formula:

$$
\mathbf{t}=\frac{\lambda}{2} \cdot \frac{\Delta X}{X}
$$

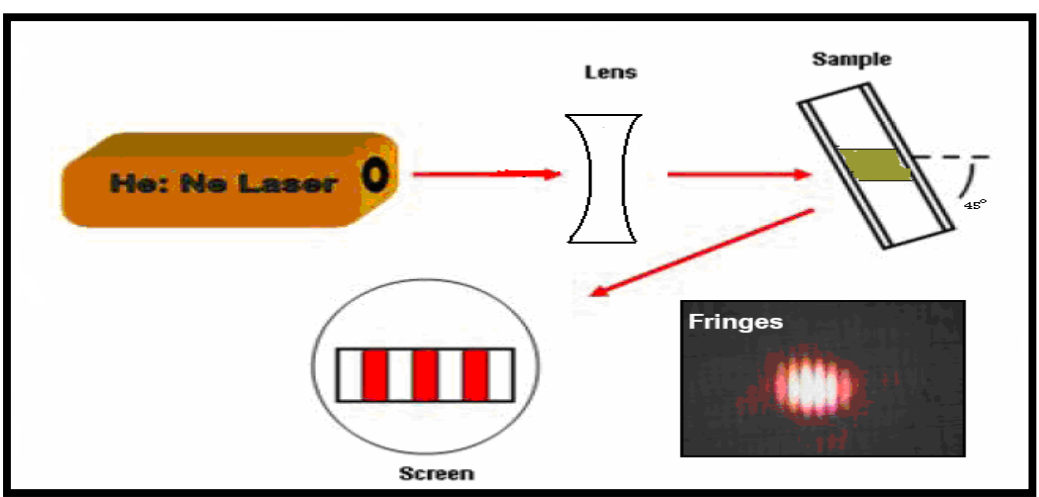

Figure 2: The schematic diagram of the film thickness measurement. 
X-ray diffraction (XRD) is the most significant techniques for qualitative and quantitative analysis of crystalline compounds and materials. This experimental technique has long been used to determine the overall structure of $\mathrm{SiO}_{2}$ thin films, including lattice constants, grain size identification of unknown materials, orientation of single crystals, and orientation of polycrystals. In this study thin films have been examined by X-ray diffraction (XRD) technique under the conditions power diffraction system with $\mathrm{Cu}$-Ka X-ray tube $(\lambda=1.54056 \AA)$ was used. The X-ray scans were performed between $2 \theta$ values of the X-ray diffraction (XRD) was recorded at a scanning rate of $0.08333^{\circ} \mathrm{s}^{-1}$ with the diffraction angle $2 \theta$, range $\left(20^{\circ}-60^{\circ}\right)$.

Optical measurements on the $\mathrm{SiO}_{2}$ thin films were performed on a UV mate SP-8001 double beam spectrophotometer covering the wavelengths range $(190-1100 \mathrm{~nm})$ supplied by Metertech Corporation (Taipei, Taiwan).

\section{RESULTS AND DISCUSSION}

X-ray diffraction investigates the structural type of the $\mathrm{SiO}_{2}$ thin films prepared by pulse laser deposition. The XRD pattern for films deposited at room temperature before annealing treatment showed that they are amorphous structure takes place. The XRD patterns for this $\mathrm{SiO}_{2}$ films are presented in figure (3).

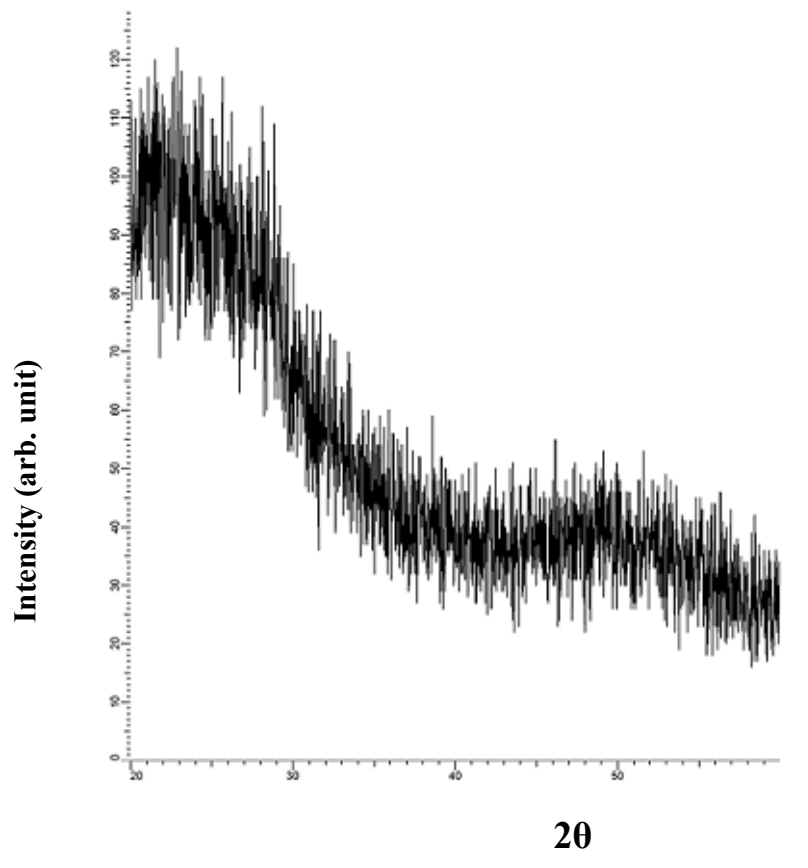

Figure 3 XRD pattern of $\mathrm{SiO}_{2}$ thin film despite of glass substrate

The optical characteristics which involve the absorption coefficient, the optical energy gap $E_{g}$, and the optical constants (i.e. refractive index $\mathrm{n}$, extinction coefficient $\mathrm{k}$, real dielectric constant $\varepsilon_{\mathrm{r}}$ and imaginary dielectric constant $\varepsilon_{\mathrm{i}}$ ), were studied within the range (200-800) $\mathrm{nm}$ for $\mathrm{SiO}_{2}$ thin deposited by PLD technique. The effect of laser pulse energy on absorbance spectra for $\mathrm{SiO}_{2}$ thin films before and after annealing are shown in figure (4) and (5) respectively. This spectrum reveals that the maximum absorption peak at (350-360) $\mathrm{nm}$ range .It is observed that as the laser pulse energy increases the absorbance increases because of the increment in thickness also, the maximum absorbance can be obtained at laser pulse energy $900 \mathrm{~mJ}$ because the thickness is maximum at $900 \mathrm{~mJ}$. 


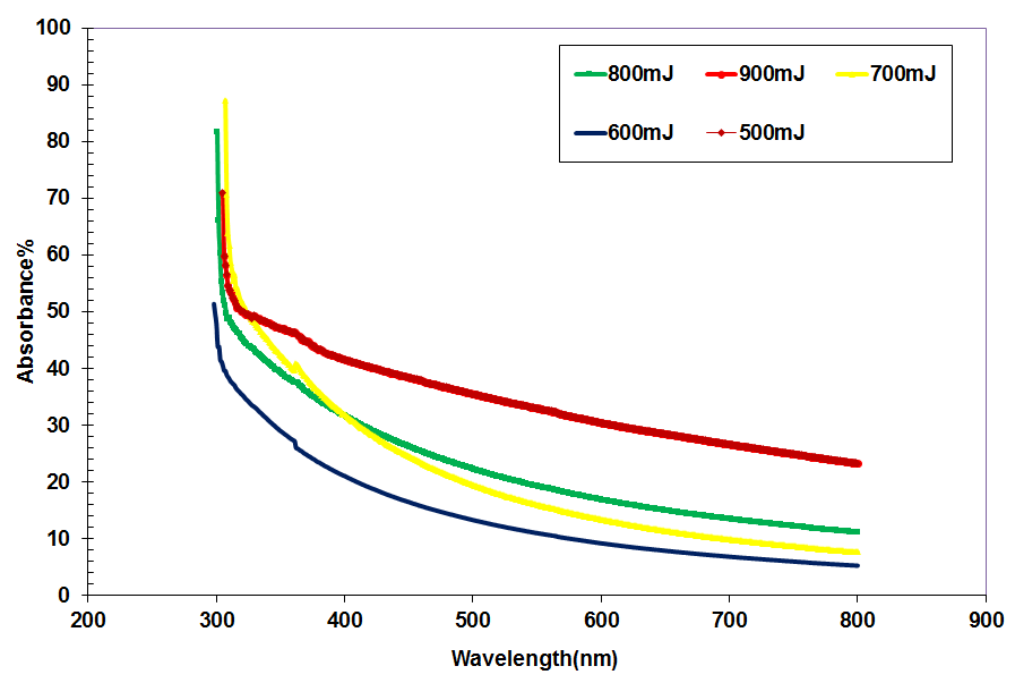

Figure 4: The optical absorbance of $\mathrm{SiO}_{2}$ thin films at different laser pulse energy before annealing process

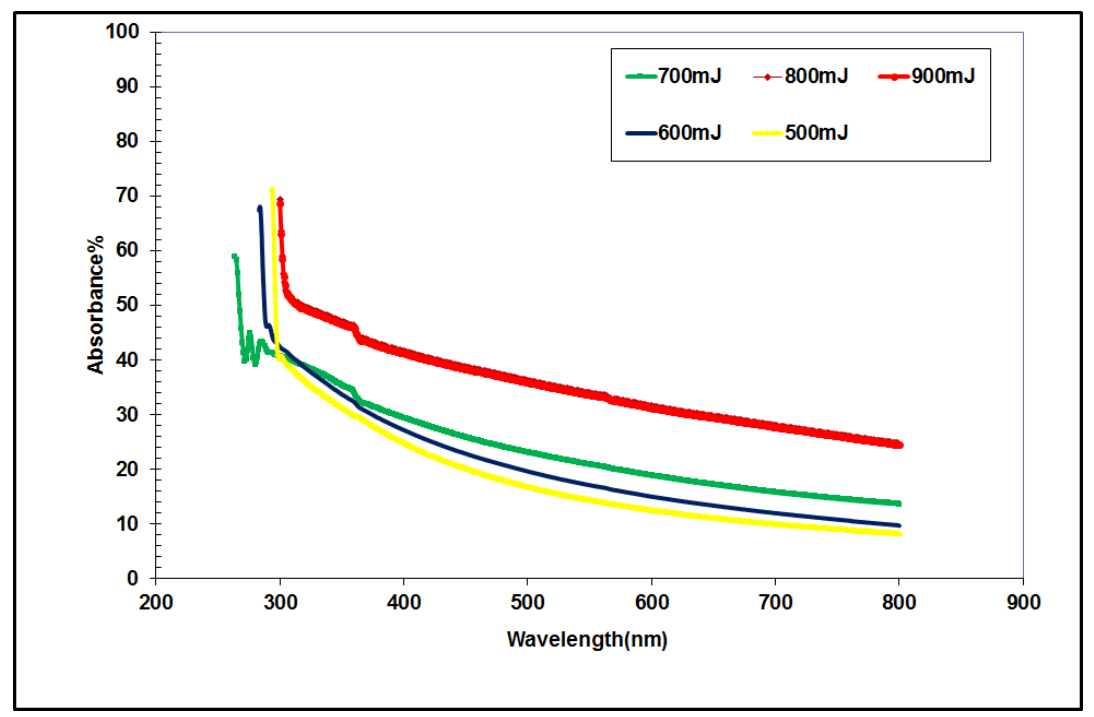

Figure 5: The optical absorbance of $\mathrm{SiO}_{2}$ thin films at different laser pulse energy after annealing process

Figure (6) and (7) show the variation of $(\alpha h v)^{2}$ as a function of (hv) for $\mathrm{SiO}_{2}$ thin films before and after annealing respectively. It can be observed from this figure that the energy gap after annealing equal from 1.7 to $3 \mathrm{eV}$ and equal from 4 to $4.16 \mathrm{eV}$ depending on the laser pulse energy, as the laser pulse energy increases the energy gap decreases, it is noticed that the annealing temperature effects on the value of direct energy gap because of the crystalline enhancement. 


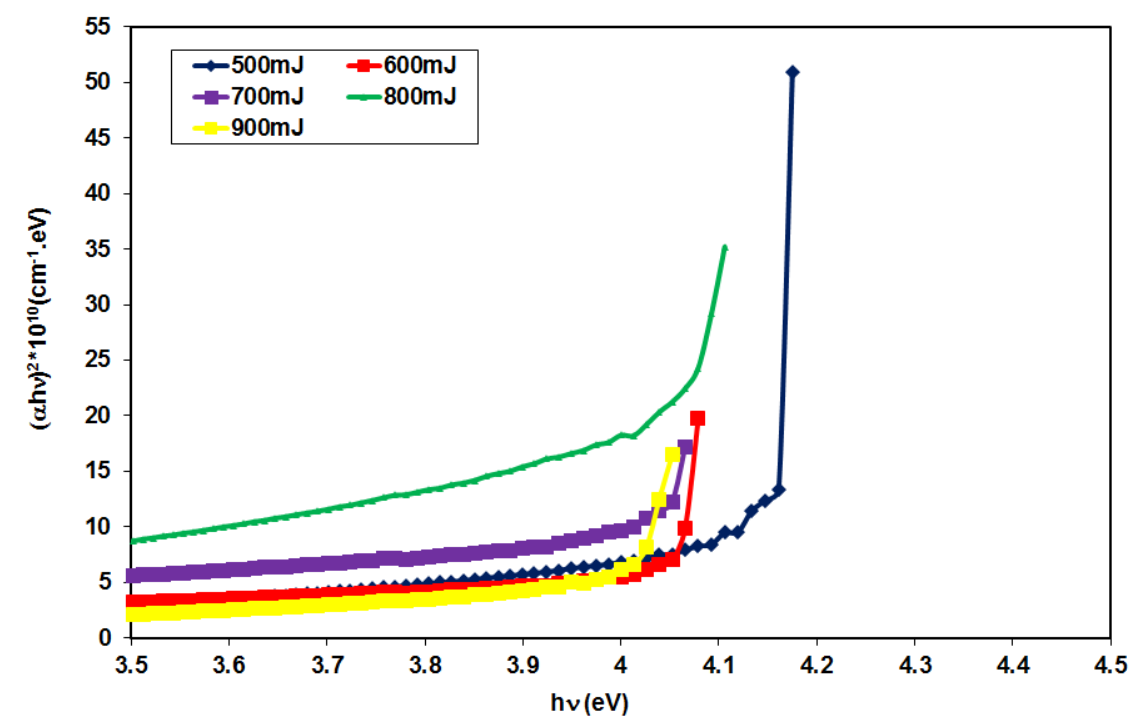

Figure 6: Variation of $(\alpha \mathrm{hv})^{2}$ versus hv for $\mathrm{SiO}_{2}$ thin films at different laser pulse energy before annealing process

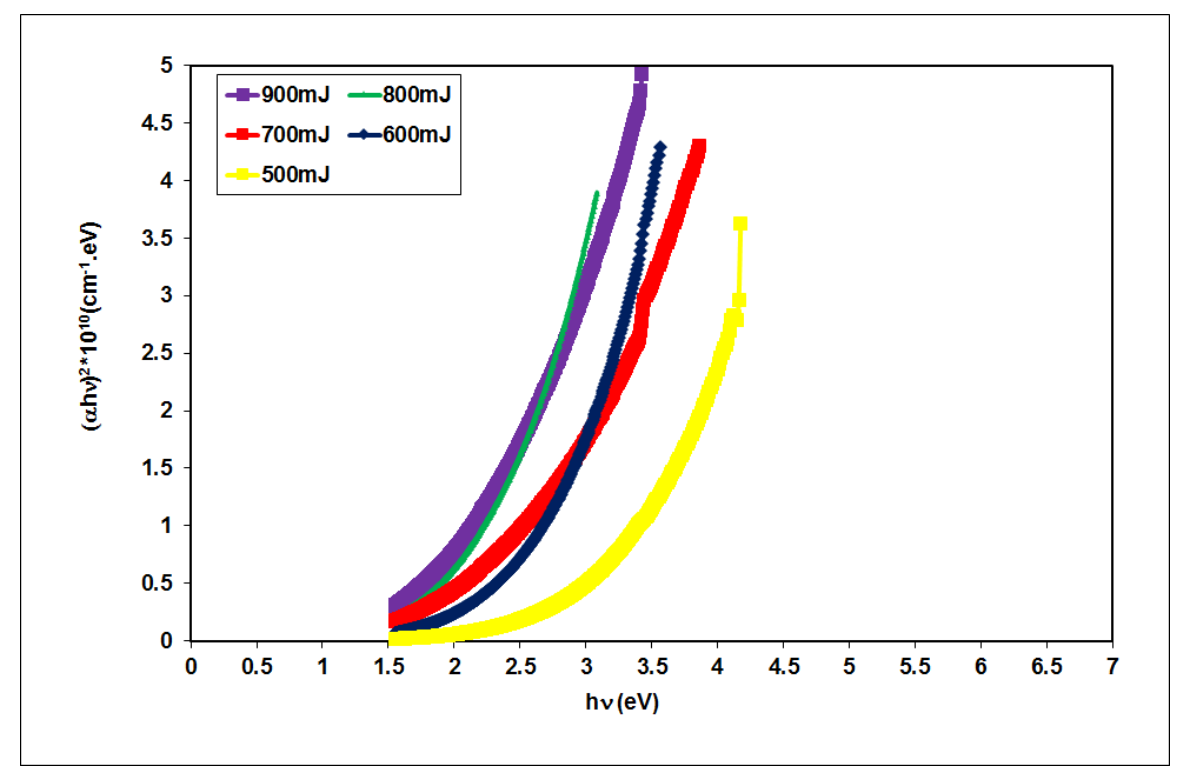

Figure 7: Variation of $(\alpha h v)^{2}$ versus hv for $\mathrm{SiO}_{2}$ thin films at different laser pulse energy after annealing process

Figure (8) and (9) show the optical reflectance spectra of $\mathrm{SiO}_{2}$ thin films before and after annealing. As shown from figures (8) and (9), as the laser pulse energy increases the reflectance of the film increases because of the increment in the thickness. 


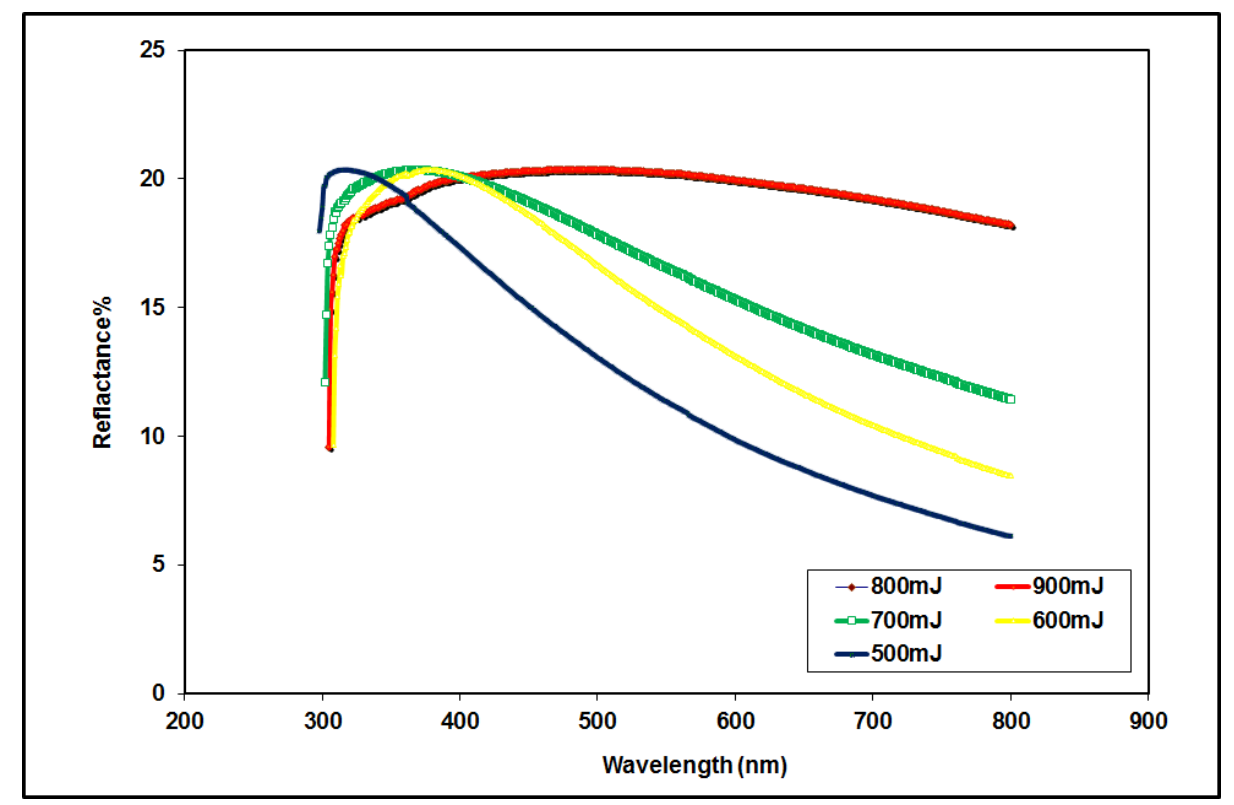

Figure 8: The Reflectance spectra for $\mathrm{SiO}_{2}$ thin films at different laser pulse energy before annealing process

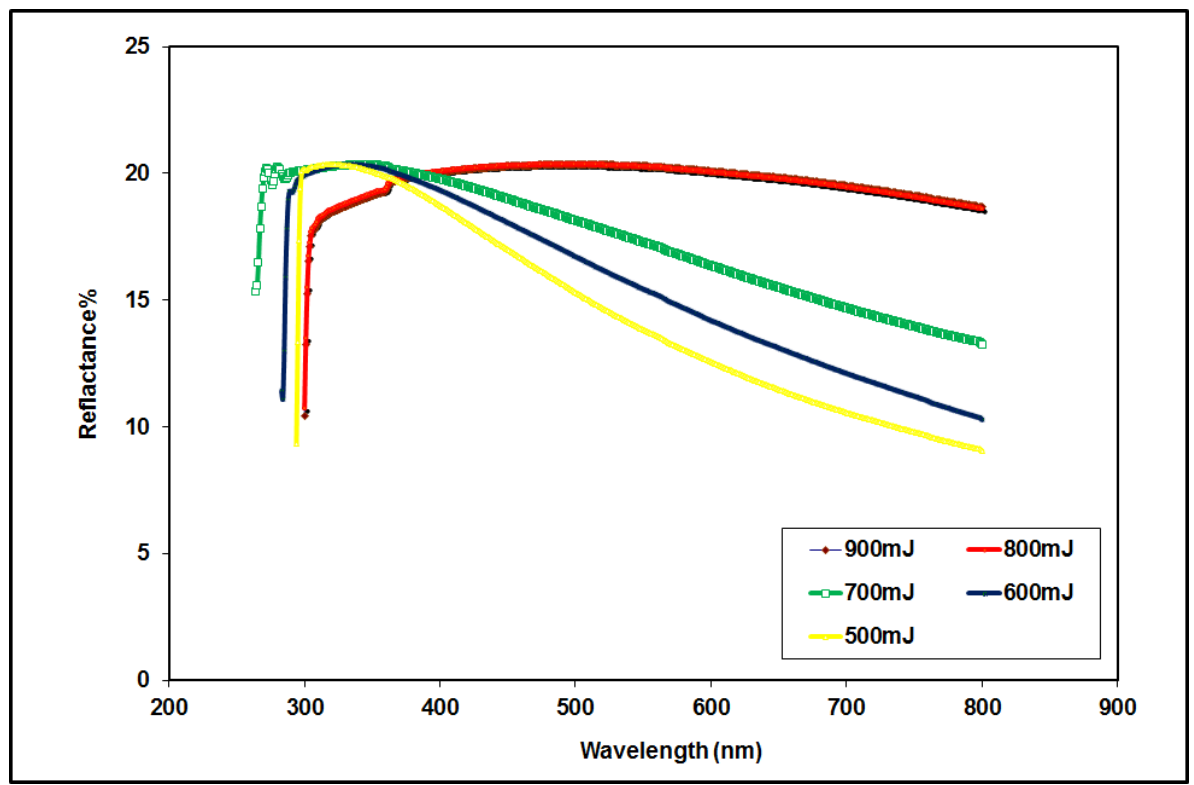

Figure 9: The Reflectance spectra for $\mathrm{SiO}_{2}$ thin films at different laser pulse energy after annealing process

The annealing process leads to increase in the reflectance because of the improvement in the morphology of the film due to the thermal process.

The optical constants which are include the of refractive index $\mathrm{n}$, extinction coefficient $\mathrm{k}$, the real $E_{r}$, and imaginary $E_{i}$ parts of dielectric constants were determined from transmission and absorption spectra within the range (200-800) $\mathrm{nm}$ for $\mathrm{SiO}_{2}$ thin films prepared by PLD before and after annealing process. Figure (10) and (11) show the variation of the refractive index as a function of the wavelength for $\mathrm{SiO}_{2}$ thin films at different laser pulse energy before and after annealing respectively. It indicates that the refractive index almost constant at range (400-600) $\mathrm{nm}$, and increases with increasing laser pulse energy. 


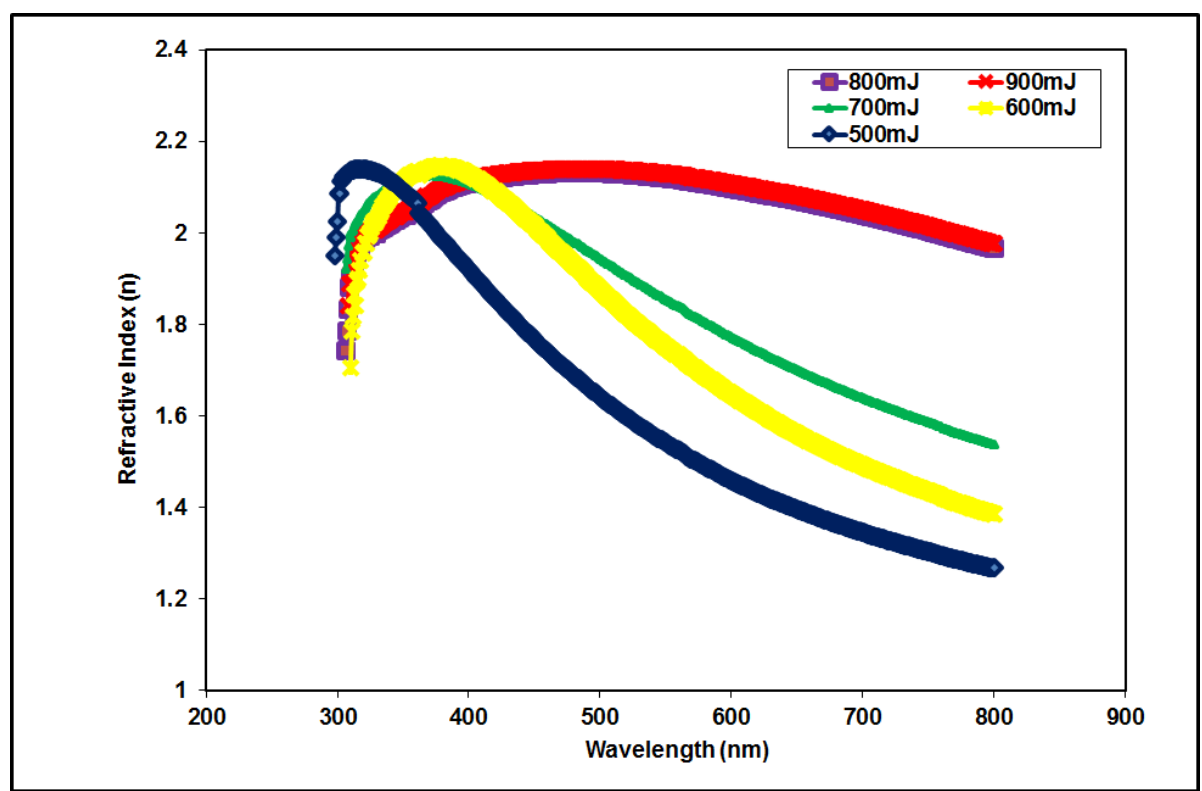

Figure 10: The Refractive index (n) for $\mathrm{SiO}_{2}$ thin films at different laser pulse energy before annealing procces

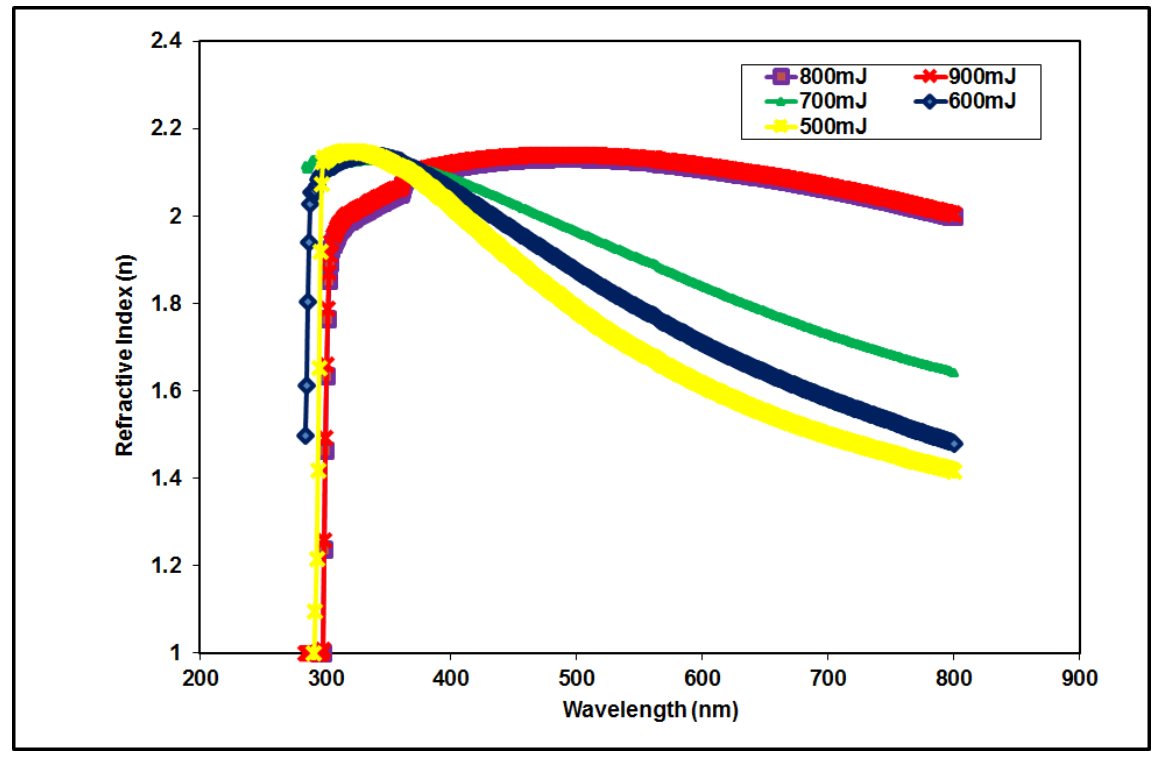

Figure 11: The Refractive index (n) for $\mathrm{SiO}_{2}$ thin films at different laser pulse energy after annealing process

The annealing treatment causes the refractive to be increased due to the improvement in the morphology of the deposited $\mathrm{SiO}_{2}$ films.

Figure (12) and (13) show the variation of extinction coefficient as a function of wave length for $\mathrm{SiO}_{2}$ Thin films under influence of laser pulse energy before and after annealing respectively. It is observed from this figure that the extinction coefficient almost constant at visible range. Also, it is observed from this figure that the extinction coefficient increases with increasing laser pulse energy because it depends on the absorption coefficient. But the less values of extinction coefficient at $300 \mathrm{~nm}$ are due to improve of the structure, also it is observed that the annealing temperature effects on the extinction coefficient. Figures (14),(15),(16) and (17) show the variation of real $\left(\epsilon_{\mathrm{r}}\right)$ and imaginary $\left(\epsilon_{\mathrm{i}}\right)$ dielectric constants for $\mathrm{SiO}_{2}$ thin films at different laser pulse energy before and after annealing respectively. One can observed that the variation of $\varepsilon_{\mathrm{r}}$ is similar trend to that of the refractive index because of the smaller value of $\mathrm{k}^{2}$ in comparison with $\mathrm{n}^{2}$, while the variation of $\varepsilon_{\mathrm{i}}$ mainly depends on the $k$ value, which are related to the variation of absorption coefficient. $\varepsilon_{\mathrm{i}}$ represent the absorption of radiation by free carriers. It is observed from the figures that the real and imaginary dielectric constants increase with the increase of laser pulse energy and 
in case of the annealing process, and this behavior is due to the change of reflectance and absorbance with change of laser pulse energy and annealing temperature.

\section{CONCLUSIONS}

In this work we have investigated the optical characteristic of $\mathrm{SiO}_{2}$ thin films prepared by PLD. The optical absorption measurement shows that the $\mathrm{SiO}_{2}$ film has a flat surface, laser pulse energy effects on the optical properties of $\mathrm{SiO}_{2}$ thin films, a direct band gap of $\mathrm{SiO}_{2}$ is found to be 3 $\mathrm{eV}$ at minimum laser pulse energy $500 \mathrm{~mJ}$ in case of annealing process at $500^{\circ} \mathrm{C}$. The optical constants absorption coefficient, extinction coefficient and optical dielectric constant, of these films were determined using transmittance and refraction spectra and they are increased as the laser pulse energy and annealing temperature increased due to the improvement of the $\mathrm{SiO}_{2}$ thin films morphology.

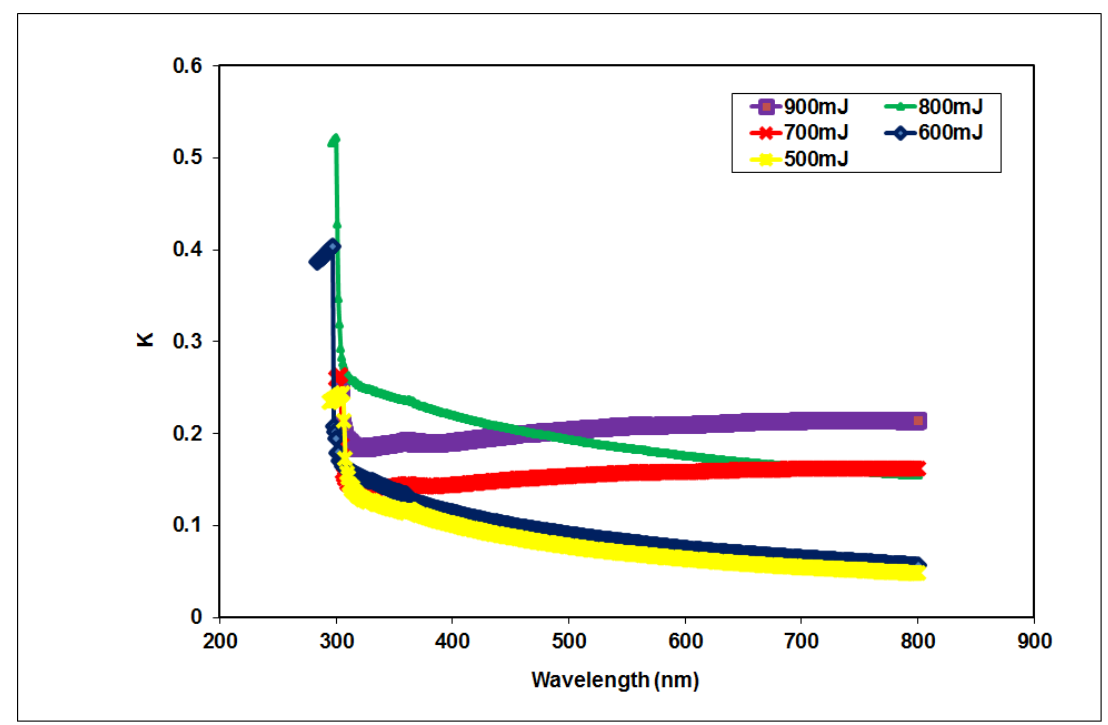

Figure 12: The Extinction coefficient for $\mathrm{SiO}_{2}$ thin films at different laser pulse energy before annealing process

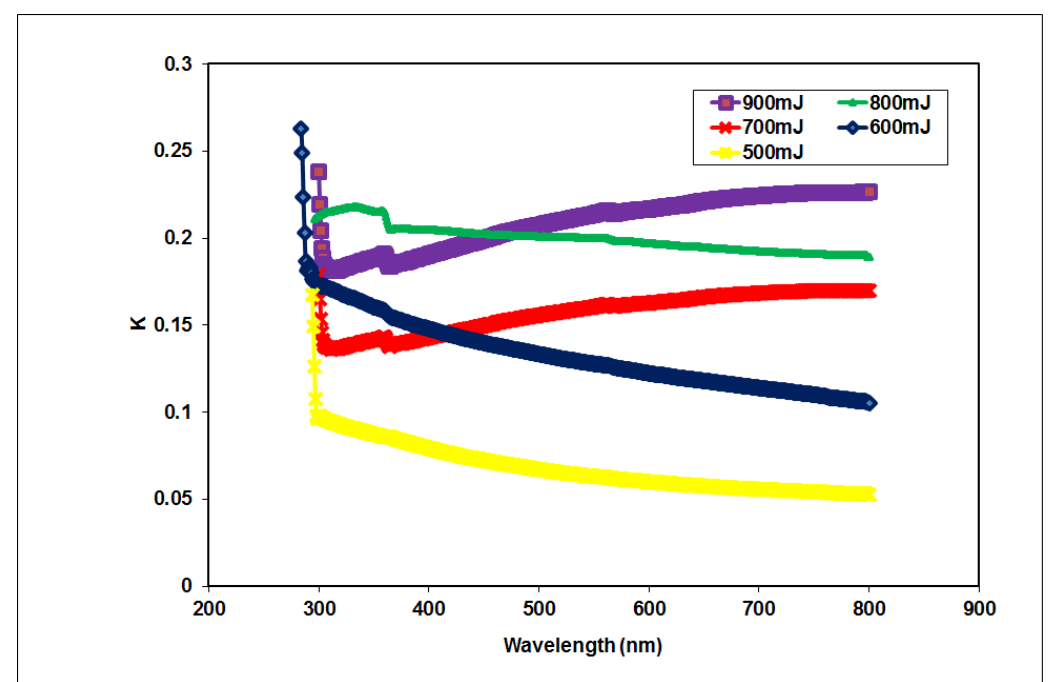

Figure 13: The Extinction coefficient for $\mathrm{SiO}_{2}$ thin films at different laser pulse energy after annealing process 


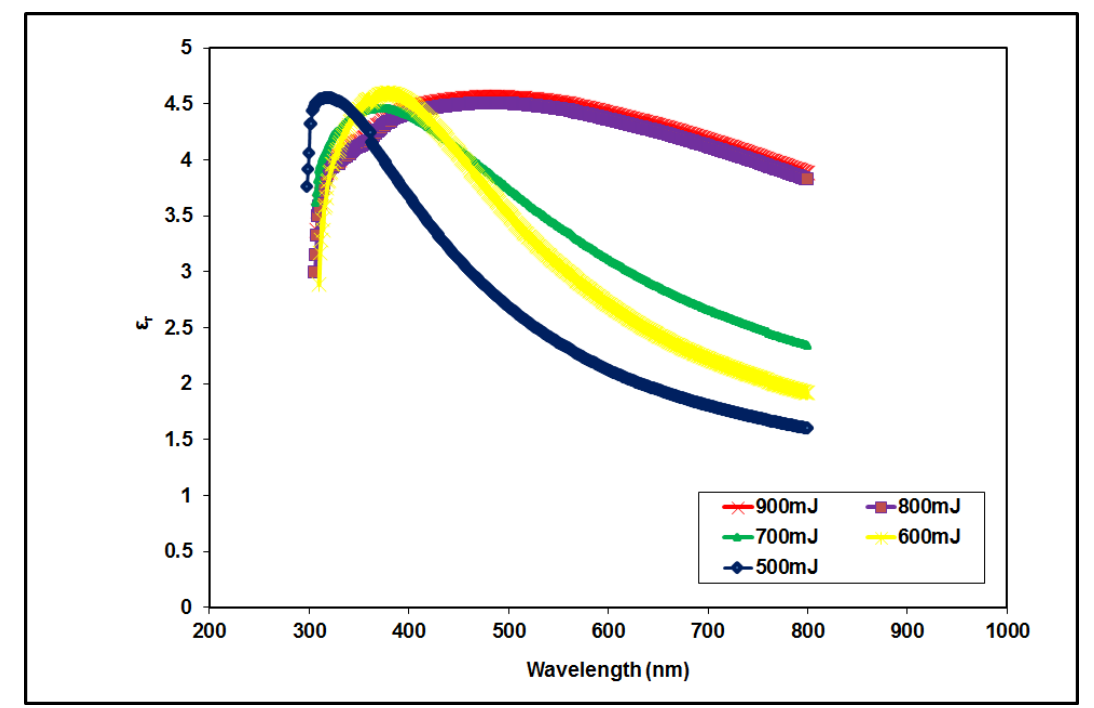

Figure 14: Real dielectric constant $\varepsilon_{\mathrm{r}}$ for $\mathrm{SiO}_{2}$ thin films at different laser pulse energy before annealing process

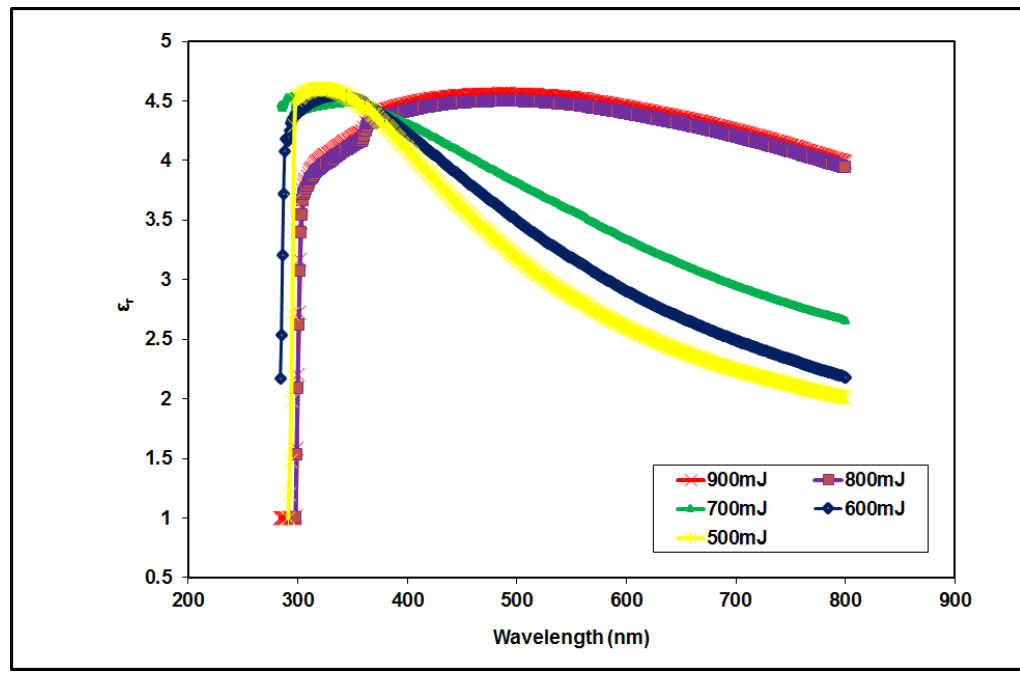

Figure 15: Real dielectric constant $\boldsymbol{\varepsilon}_{\mathbf{r}}$ for $\mathrm{SiO}_{2}$ thin films at different laser pulse energy after annealing process

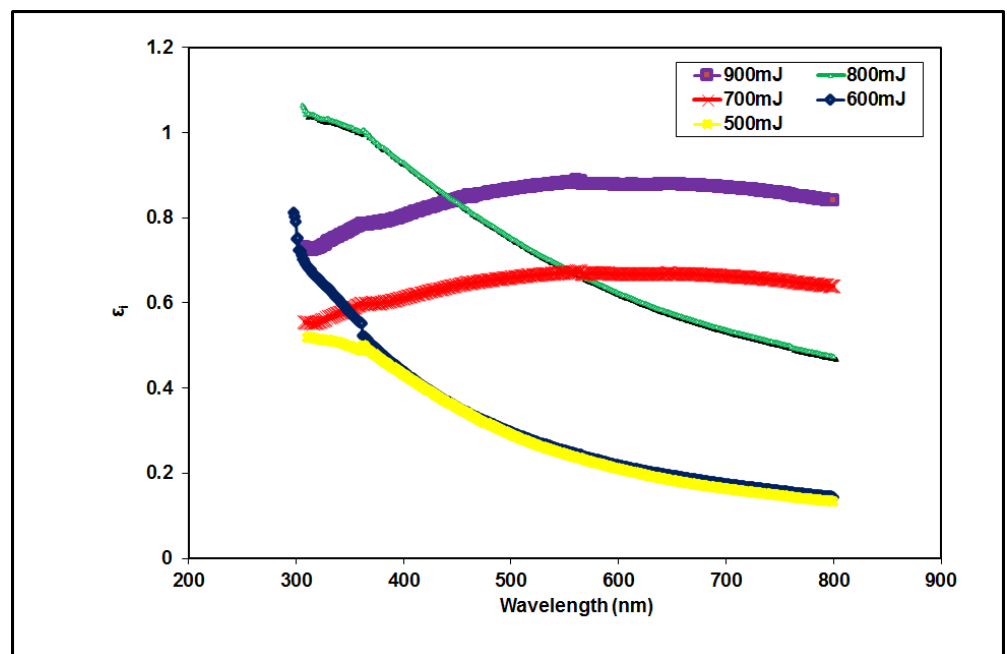

Figure 16: Imaginary dielectric constant $\boldsymbol{\varepsilon}_{\mathbf{i}}$ for $\mathrm{SiO}_{2}$ thin film at different laser pulse energy before annealing process 


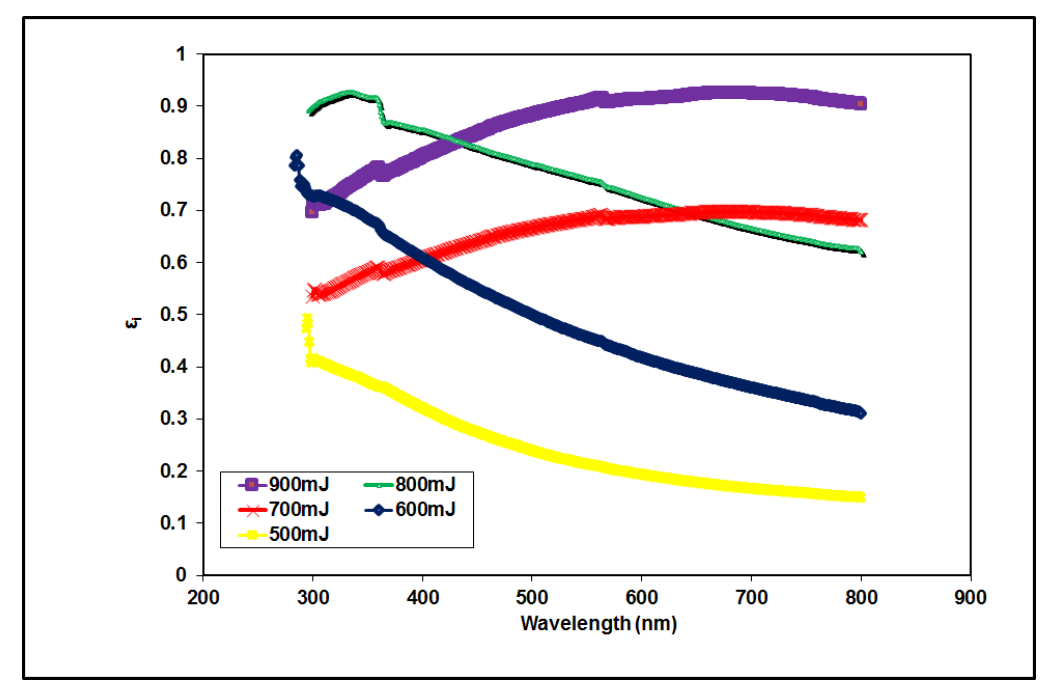

Figure 17: Imaginary dielectric constant $\boldsymbol{\varepsilon}_{\mathbf{i}}$ for $\mathrm{SiO}_{2}$ thin film at different laser pulse energy after annealing process

\section{Reference}

[1] Douglas B. Chrisey and Graham K. Hubler, "Pulsed Laser Deposition of Thin Flms", Wiley Interscience, New York, 199 (1994).

[2] Dijkamp, D., R. Venkatesan, X.D. Wu, S.A. Shaheen, N. Jisrawi, Y.H. Min-Lee, W.L. Mc-, and M. Croft, "Preparation of Y-Ba-Cu oxide superconductor thin films using pulsed laser evaporation from high Tc bulk material", Appl. Phys. Lett. 51 (8), 619-621 (1987).

[3] Chrisey, D.B., J.S. Horwitz, J.M. Pond, R.C.Y. Auyeung, P.C. Dorsey, S.B. Qadri, L.A. Knauss, C.H. Mueller, and R.M. Yandrofski, "Active microwave device applications of ferroelectric thin films", SPIE Vol. 2403, 164-174 (1995).

[4] Chrisey, D.B., P.C. Dorsey, J.S. Horwitz, L.A. Knauss, and R.C.Y. Auyeung, "Pulsed laser deposition of thick films of electronic cerarnics", SPIE Vol. 2703, 386-397 (1996).

[5] Jin, S., T.H. Tiefel, M. McCormack, R.A. Fastnacht, R. Ramesh, and L.H. Chen, "Thousandfold change in resistivity in magnetoresistive La-Ca-Mn-O films", Science Vol. 264,413-415 (1994).

[6] Horwitz, J.S., P.C. Dorsey, N.C. Koon, M. Rubinstein, J.M. Byers, D.J. Gillespie, M.S. Osofsky, V.G. Harris, K.S. Grabowski, D.L. hies, E.P. Donovan, R.E. Treece, and D.B. Chrisey, "The effect of oxygen deposition pressure and temperature on the structure and properties of pulsed laser deposited $\mathrm{La}_{0.67} \mathrm{Ca}_{0.33} \mathrm{MnO}_{\delta}$ films", SOPI,E Vol. 2703,526-533 (1996).

[7] Antoni, F., C. Fuchs, and E. Fogarassy, "Analytical description of the film thickness distribution obtained by the pulsed laser ablation of a monatomic target: application to Silicon and germanium", Appl. Surf. Sci. 96-98,50-54 (1996).

[8] Cillessen, J.F.M., R.M. Wolf, J.B. Giesbers, P.W.M. Blom, K.-O. Grosse-Holz, and E. Pastoor, "Growth, structuring and characterisation of all-oxide thin film devices prepared by pulsed laser deposition", Appl. Surf. Sci. 96 98,744-751 (1996)

[9] Chergui, A., J.L. Deiss, J.B. Grun, J.L. Loison, M. Robino, and R. Beseman, "Structural and optical characteristics of pulsed laser deposited ZnSe epilayers", Appl. Surf. Sci. 96998,874-880 (1996).

[10] Xiao, R.F., H.B. Liao, N. Cue, X.W. Sun, and H.S. Kwok, "Growth of c-axis oriented gallium nitride thin films on an amorphous substrate by the liquid-target pulsed laser deposition technique", J. Appl. Phys. 80 (7), 4226-4228 (1996).

[11] Narayan, J., H. Wu, and R.D. Vispute, "Laser processing of BN and AIN films", J. of EIec. Mat. 25 (1), 143-149 (1996).

[12] Feiler, D., R.S. Williams, A.A. Talin, H. Yoon, and M.S. Goorsky, "Pulsed laser deposition of epitaxial AlN, GaN, and InN thin films on sapphire(0001)", J. of Crystal Growth 171, 12-20 (1997). 
[13] Craciun, V., S. Amirhaghi, D. Craciun, J. Eldars, J.G.E. Gardeniers, and I.W. Boyd, "Effects of laser wavelength and fluence on the growth of Zn0 thin films by pulsed laser deposition", Appl. Surf. Sci. 86,99-106 (1995).

[14] Durand, H.-A., J.-H.B rimaud, O. Hellman, H. Shibata, S. Sakuragi, Y. Makita, D. Gesbert, and P. Meyrueis, "Excimer laser sputtering deposition of $\mathrm{TiO}_{2}$ optical coating for solar cells", Appl. Surf. Sci. 86, 122- 127 (1995).

[15] Afonso, C.N., J.M. Ballesteros, J. Gonzalo, G.C. Righini, and S. Pelli, "Rare-earth doped glass waveguides prepared by pulsed laser deposition", Appl. Surf. Sci. 96-98, 760-763 (1996).

[16] Reisse, G., S. Weissmantel, B. Keisser, and B. Steiger, "Deposition of optical coatings by pulsed laser ablation", SPIE Vol. 2403,212-222 (1995).

[17] Friedmann, T.A., D.R. Tallant, J.C. Barbour, J.P. Sullivan, M.P. Siegal, R.L. Simpson, J. Mikkalson, and K.F. McCarty, "Characterization of carbon nitride films produced by pulsed laser deposition", Mat. Res. Soc. Symp. Proc. Vol. 388, 393-398 (1995).

[18] Zhang, Z.J., S. Fan, J. Huang, and C.M. Lieber, "Pulsed laser deposition and physical properties of carbon nitride thin films", J. of Elec. Mat. 25 (1), 57-61 (1996).

[19] Puretzky, A.A., D.B. Geohegan, GE. Jellison Jr., and M.M. McGibbon, "Amorphous diamondlike carbon film growth by KrF- and ArF- excimer laser PLD: correlation with plume properties", Mat. Res. Soc. Symp. Proc. Vol. 388, 145-150 (1995).

[20] Lowndes, D.H., D.B. Geohegan, A.A. Puretzky, D.P. Norton, C.M. Rouleau, "Synthesis of Novel Thin-Film Materials by Pulsed Laser Deposition", Science Vol. 273, 898-903 (1996).

[21] B. D. Jackson, "Pulsed-Laser Deposition of Silicon Dioxiode Thin-Films Using the Molecular Flourine Laser", M.Sc. thesis, University of Toronto, Canada, (1997).

[22] Fair, R.B., "Conventional and rapid thermal processes", in US1 Technology, edited by C.Y. Chang and S.M. Sze, McGraw-Hill Companies, Iric., New York, 144-204 (1996).

[23] Fogarassy, E., A. Slaoui, C. Fuchs, and J.P. Stoquert, "Synthesis of Si02 thin films by reactive excimer laser ablation", Appl. Surf. Sci. 54, 180- 186 (1992).

[24] Slaoui, A., E. Fogarassy, C. Fuchs, and P. Siffert, "Characterization of SiO2 films deposited by reactive excimer laser ablation of Si0 target", paper presented at INFOS '91, Liverpool, April 199 1, Contributed Papers, Section 3, 195- 198 (1991).

[25] Slaoui, A., E. Fogarassy, C. Fuchs, and P. Siffert, "Properties of silicon dioxide films prepared by pulsed-laser ablation", J. Appl. Phys. 71 (2), 590-596 (1992).

[26] Wolf, P.J., "The plasma properties of laser-ablated SiOs', J. Appl. Phys. 72 (4), 1280-1289 (1992).

[27] Baeri, P., R. Reitano, and N. Marino, " $\mathrm{SiO}_{2}$ film deposition by $\mathrm{XeCl}$ laser ablation of fused silica", App. Surf. Sci. 86, 128-133, (1995). 